\title{
Crisis in the Case Study Crisis: Marginal Diminishing Returns to Scale in the Quantitative-Qualitative Research Debate
}

\author{
J. L. King \\ Center for Research on Information Technology \\ and Organizations (CRITO) \\ University of California \\ Irvine, California 92697 USA \\ Tel: (714) 824-5244 \\ Fax: (714) 824-8091 \\ E-mail: king@ics.uci.edu \\ L. M. Applegate \\ Harvard Business School \\ Baker West 182 \\ Soldiers Field \\ Boston, Massachusetts 02163 USA \\ Tel: (617) 495-6362 \\ Fax: (617) 496-2910 \\ E-mail: lapplegate@hbs.edu
}

Abstract

The quest for legitimation of research approaches preoccupies many information systems researchers. Researchers who have adopted various forms of "qualitative" research seem particularly concerned about legitimating their work. This desire for 
legitimation is stimulated in part by ongoing debates about the nature of human understanding and the way we come to know about the world. In healthy circumstances this produces a useful, self-critical discussion that heads to improvements in the development and execution of research projects. Often, however, these debates are facades. They cover an underlying political struggle for position within the broad patronage structure of the academic world. Certain approaches are seen as "better" - more scientific, more rigorous, more formal, more pure - while others are marginalized as weak, journalistic, and even "atheoretical." These political dynamics are compounded by practical considerations (e.g., the length of time and cost required to conduct rigorous case research and the need for access to managers within companies) and the requirement for a researcher to have achieved a certain level of management and business sophistication to effectively collect and analyze qualitative data.

These realities serve as powerful barriers to case research for all academics. For doctoral students and nontenured faculty, these obstacles are often insurmountable. As a result, few doctoral programs teach students to conduct rigorous qualitative research and the body of knowledge on how to conduct and evaluate such research is not well developed. It is no surprise that qualitative research is viewed as a privilege reserved for those with tenure.

All of this comes at a time when the need for qualitative research is reaching crisis proportions. Faced with a fast-paced, rapidly-changing and complex environment, managers are placing increasing pressure on educational institutions to prepare students to deal with current business realities. Faculty are expected to be knowledgeable of the issues facing managers in the 1990s and to be able to offer solutions to these problems. They are expected to deal with these issues in a holistic manner, rather than segmenting knowledge along narrow functional and discipline-based lines. This type of knowledge is best developed through qualitative, field research that enables deep understanding of a complex phenomena. But, with the tenure clock ticking and a fundamental lack of the skills and understanding required to conduct this type of research, most untenured faculty are forced to fall back on traditional, quantitative research methods.

This paper presents the dilemma faced by an untenured faculty member who is deeply interested in a research problem that is best explored through case research. Through the struggles of the new Assistant Professor, the paper explores the epistemological, political and methodological debates that surround qualitative, case research. The paper is constructed for academic legitimacy in the information systems field. The paper is constructed as a hypertext document and is available in full on the World Wide Web. Access pointers can be obtained from the web site www.isr.uci.edu and can be searched for by the word "ducktest" in any of the commonly used search engines. 


\section{BIOGRAPHY}

John L. King's current research focuses on the development of high-level requirements for information systems design and implementation. This research is informed by study of the ways in which organizational and institutional forces shape how information technology is developed (including what gets developed) and how the technologies that do get developed change the course of organizational and institutional behavior. The research draws on the fields of economics and other social sciences as well as the engineering sciences. The goal of the work is to improve the design of information technologies for both organizational and institutional usability, through better articulating the processes of requirements analysis, specification, and prototype creation. The work also informs policy and strategy development at the firm, sectoral, and institutional levels. Current projects include a study of institutional policies in shaping global and national information infrastructure in the U.S., Asia and Europe; a study of the evolution of systems requirements in intermodal transport and logistics; examination of California criminal courts as a venue of computersupported cooperative work implementation; and study of the technical and institutional co-evolution of standards and technical infrastructure in global land-line and cellular telephony. Dr. King is Professor in both Information and Computer Science the Graduate School of Management at the University of California, Irvine, and is Editor-in-Chief of Information Systems Research, a leading academic journal published. He holds a Ph.D. in Administration from the University of California, Irvine.

Lynda M. Applegate is a Professor of Business Administration at Harvard Business School. The focus of her research and teaching is the impact of information technology on organizations, industries and markets. She has authored or coauthored two books, over 25 articles and over 140 business cases and related teaching materials (including videotapes and software) on this topic. Several of her papers have won awards as the best paper at leading information systems and management conferences and a number of her cases are HBS Publishing best sellers. Lynda is a senior editor for MIS Quarterly, an Associate Editor for The Journal of Organizational Computing and Electronic Commerce, and is on the editorial board of Organization Science. She is on the Board of Directors of MicroAge, Inc. and is on the Strategic Advisory Boards of Mainspring Communications (an Internet start-up) and the Alliance Analyst. Lynda was recently appointed to the Information Technology Council, an advisory board that assists the Congress in defining U.S. information policy. 